\title{
The role of BRCA1 in homologous recombination repair in response to replication stress: significance in tumorigenesis and cancer therapy
}

\author{
Junran Zhang
}

\begin{abstract}
Germ line mutations in breast cancer gene 1 (BRCA1) predispose women to breast and ovarian cancers. Although BRCA1 is involved in many important biological processes, the function of BRCA1 in homologous recombination (HR) mediated repair is considered one of the major mechanisms contributing to its tumor suppression activity, and the cause of hypersensitivity to poly(ADP-ribose) polymerase (PARP) inhibitors when BRCA1 is defective. Mounting evidence suggests that the mechanism of repairing DNA double strand breaks (DSBs) by HR is different than the mechanism operating when DNA replication is blocked. Although BRCA1 has been recognized as a central component in HR, the precise role of BRCA1 in HR, particularly under replication stress, has remained largely unknown. Given the fact that DNA lesions caused by replication blockages are the primary substrates for HR in mitotic cells, functional analysis of BRCA1 in HR repair in the context of replication stress should benefit our understanding of the molecular mechanisms underlying tumorigenesis associated with BRCA1 deficiencies, as well as the development of therapeutic approaches for cancer patients carrying BRCA1 mutations or reduced BRCA1 expression. This review focuses on the current advances in this setting and also discusses the significance in tumorigenesis and cancer therapy.
\end{abstract}

Keywords: BRCA1, Homologous recombination, Replication arrest, Poly(ADP-ribose) polymerase (PARP) inhibitor, DNA double strand breaks, Sister chromatid exchange

\section{Two ended-DSB repair by HR: gene conversion (GC) versus crossover}

DNA lesions result from errors in normal DNA replication, production of reactive oxygen species, and exposure to ultraviolet rays and ionizing radiation (IR). The damage induced by endogenous or exogenous insults can be base damages, single strand breaks (SSBs), DSBs, and intrastrand or interstrand cross-links [1]. The inability to properly repair damaged DNA can lead to genomic instability, a hallmark of cancer. To avoid the consequence of unrepaired DNA damage, multiple types of DNA repair mechanisms exist in cells to repair the various types of DNA damage on a regular basis, including base excision repair (BER), nucleic acid excision repair (NER), HR, single strand annealing (SSA), mismatch repair (MMR) and non-homologous end joining (NHEJ)

Correspondence: junran.zhang@case.edu

Department of Radiation Oncology, School of Medicine, Case Western Reserve University, 10900 Euclid Avenue, BRB 323, Cleveland, OH 44106, USA
[1]. HR is required for repairing multiple types of DNA damage including single stranded DNA (ssDNA), DSBs and DNA cross-links. In addition, HR is a critical mechanism for recovery of stalled or broken DNA replication forks. Certain genetic alterations, such as BRCA1 and BRCA2 mutations, are associated with increased risk of malignancy and enhanced sensitivity to chemotherapeutic agents, including PARP inhibitors. This review focuses on mechanistic aspects of the function of BRCA1 in HR repair following replication stress, and also the implications to tumor development and cancer therapy.

HR mediated repair can be triggered by DNA DSBs and blockages of DNA replication. The process of repairing DNA DSBs by HR has been extensively studied in both lower and higher organisms. In general, recombination is initiated at DSBs with the nucleolytic degradation of DNA ends to generate 3 -end ssDNA. This reaction is carried out by the MRE11/RAD50/NBS1 $(\mathrm{MRN})$ complex [2,3]. CtIP plays a critical regulatory 
role in ssDNA resection, along with the MRN complex [4]. Once ssDNA is generated, it is rapidly bound by the ssDNA-binding-protein RPA, a protein consisting of three subunits: RPA1, RPA2 and RPA3. Through the action of recombination mediator/comediator proteins, RPA coated ssDNA is displaced by the RAD51 protein, a human homologue of E. coli RecA. The formed RAD51 nucleoprotein filament facilitates DNA strand invasion and exchange steps [5] which leads to formation of a Holliday junction (HJ) (Figure 1). From this point, the DSBR (double-strand break repair) pathway and the SDSA (synthesis-dependent strand annealing) pathway are defined. They are two primary models for how HR repairs two ended DSBs [6]. In the DSBR pathway, the second $3^{\prime}$ overhang also forms an $\mathrm{HJ}$ with the homologous chromosome, which most frequently is a sister chromatid. Whether recombination in the DSBR pathway results in crossover is determined by how the double HJs are resolved by a restriction endonuclease, a resolvase [7], which cuts only one DNA strand. RAD51C is an identified resolvase in mammalian cells [8]. Crossover occurs if one $\mathrm{HJ}$ is cut on the crossing strand and the other $\mathrm{HJ}$ is cut on the non-crossing strand (Figure 1). Alternatively, if the two HJs are cut on the crossing strands, gene conversion (GC) occurs without a crossover [9]. The DSBR pathway more frequently results in a crossover than GC (Figure 1). In the SDSA pathway, only GC occurs because the first invading $3^{\prime}$ strand is extended along the recipient DNA duplex by a DNA polymerase, and is released as the $\mathrm{HJ}$ resolves via branch migration.

\section{DNA replication-associated lesions are repaired by HR via crossover}

The lesions occurring at stalled/collapsed replication forks can be repaired by HR or bypassed by translesion DNA synthesis (TLS). The HR mechanism required for repairing lesions at stalled or collapsed DNA replication forks in mammalian cells is less well-understood compared to the pathways identified in bacteria and yeast. There are several models available depending on whether the lesion occurs in the leading or lagging strands. If the lesion occurs in leading strands, stalled replication forks can be cleaved by an endonuclease, leading to the creation of a one-sided DSB. Similar to the RuvABC complex in E. coli [10], the endonuclease Mus81 facilitates one ended DSB generation in mammalian cells $[11,12]$. One-sided DSB repair by recombination involves

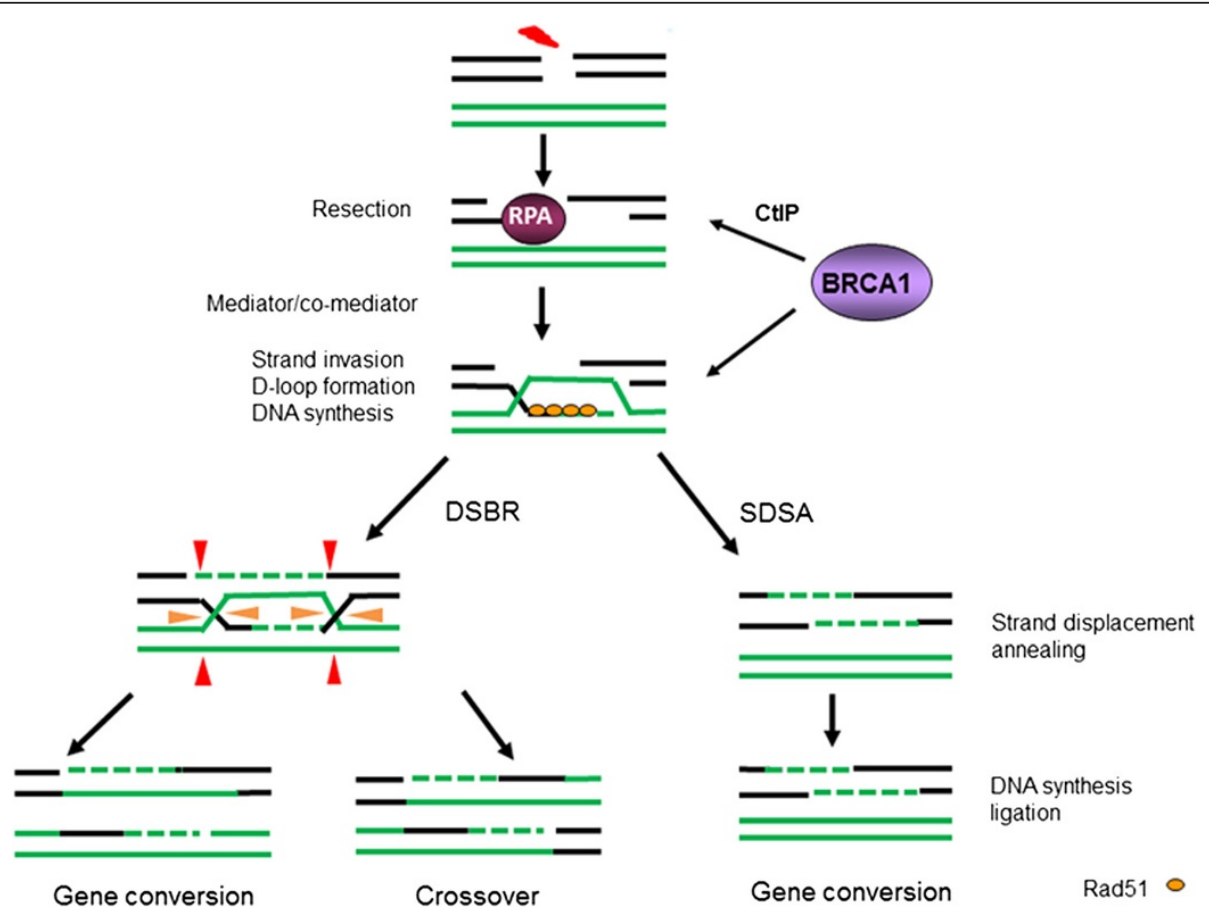

Figure 1 DSBs can be repaired by several HR repair pathways including DSBR (double-strand break repair) and SDSA (synthesisdependent strand annealing). HR is initiated by resection of a DSB to provide 3' ssDNA overhangs. Strand invasion by these 3' ssDNA overhangs into a homologous sequence is followed by DNA synthesis at the invading end. After strand invasion and synthesis, the second DSB end can be captured to form an intermediate with two HJs. After gap-repair DNA synthesis and ligation, the structure is resolved at the HJs in a non-crossover (red arrow heads at both HJs) or crossover mode (orange arrow heads at one $\mathrm{HJ}$ and red arrow heads at the other $\mathrm{HJ}$ ). Alternatively, the reaction can proceed to SDSA by strand displacement, annealing of the extended single-strand end to the sSDNA on the other break end, followed by gap-filling DNA synthesis and ligation. The repair product from SDSA is always non-crossover. 


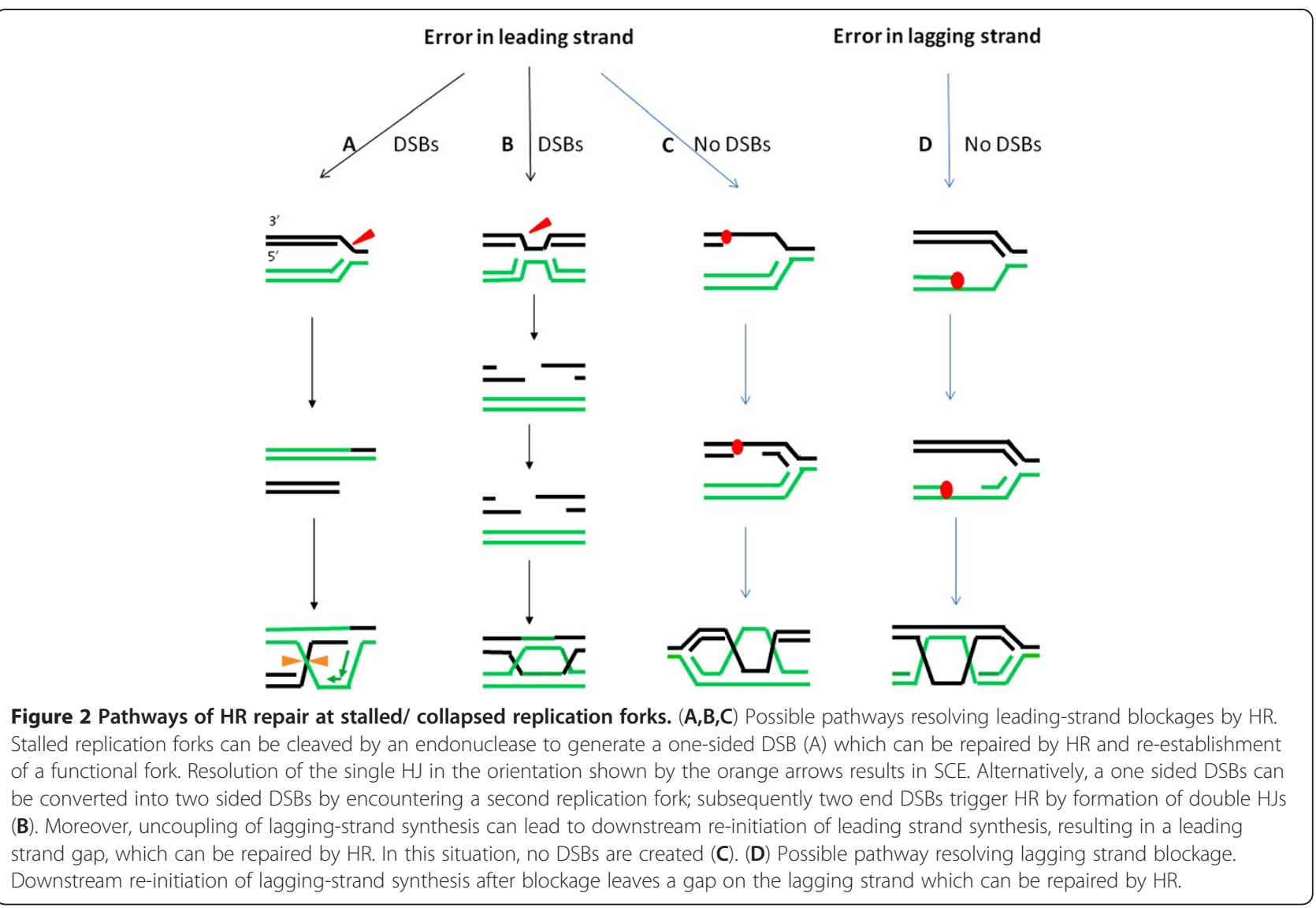

DNA strand invasion and one $\mathrm{HJ}$ formation (Figure 2A). A crossover is generated when the $\mathrm{HJ}$ structure is resolved [13]. Alternatively, a one-ended DNA DSB could subsequently progress to a two-ended DSB due to the firing of a new origin of replication under conditions of replication stress, and $\mathrm{HR}$ will be initiated to repair a structure that is similar to the classical two-end DSB (Figure 2B) [14]. In both situations (Figure 2A,B), DSBs are involved. In contrast, no DSBs are generated if uncoupling of continued lagging-strand synthesis with stopped leading strand synthesis occurs. Downstream re-priming of leading strand synthesis will result in the leading strand gap, and can be subsequently be repaired by recombination $[10,15,16]$ (Figure $2 C$ ). If a lesion leads to lagging strand blockage (Figure 2D) the replication fork may not collapse. Downstream re-priming of lagging-strand synthesis after blockage leaves a gap on the lagging strand, which can be repaired by recombination [10]. Although it was reported that creation of DNA DSBs leading to replication fork collapse is a major mechanism to initiate HR in mammalian cells [14,17], it has been demonstrated that thymidine can potently induce HR in the absence of DSBs even after long term exposure [18]. Recent work from our lab showed that sister chromatid exchange (SCE, see discussion below) is induced when the cells are treated with $2 \mathrm{mM}$ hydroxyurea (HU) for $6 \mathrm{hr}$, a condition in which no DSBs are detected by Comet assay or FISH [19]. Similar to lower organisms, therefore, HR can be induced in the absence of free DNA DSB ends in mammalian cells.

Broken replication fork-stimulated HR may be different than HR induced by classical two-end DNA DSBs. Two-end DNA DSBs created by site-specific I-SceI endonuclease overexpression in mammalian cells triggers HR repair by short gene conversion [20], whereas spontaneous HR, most likely occurring at replication forks, triggers repair via a SCE [21,22]. In addition, the product of HR induced by replication stress is SCE/long tract gene conversion [21,22]. Moreover, we have found that phosphorylation of RPA2 is specifically required for HR in response to replication arrest, but is not essential for the cutting two-end DSBs induced HR [23]. Further, GC detected by an I-SceI based HR reporter is promoted by ATR, while SCE induced by replication fork collapse is suppressed by ATR [19]. These studies suggest that HR pathways required for repairing direct DSBs and replication blockage are distinct. Furthermore, HR pathways required for repairing replication fork stalling and collapse appear to be different as well. We have found that SCE induced by DSBs following fork collapse is suppressed by 
ATR, whereas the frequency of SCE induced by replication fork stalling is similar in cells with or without ATR depletion [19]. The complexity of the HR pathway was further increased by the observation that mouse cells lacking DNA POL $\beta$, the major gap-filling DNA polymerase, display higher than normal SCE levels following alkylating agent exposure, although they exhibit normal levels of spontaneous SCE [13]. Also some HR proteins required for replication stress-induced SCE have no obvious effect in spontaneous SCE (see discussion below). In summary, HR repair pathways triggered during DNA replication blockage are differently regulated than those induced by direct DNA DSBs. In addition, several subtypes of the HR pathway exist to deal with spontaneous and induced DNA lesions resulting from replication fork stalling or collapse.

\section{SCEs are associated with DNA replication and HR}

HR requires a template with sufficient sequence identity to the damaged strand in order to direct repair. In mammalian cells, the sister chromatid is the primary template for HR compared to the homologous chromosome [20]. SCEs occur naturally as events associated with normal DNA replication and upon replication fork stalling/collapse. Formation of SCEs is intimately associated with DNA replication because eukaryotic cells exposed to DNA-damaging agents in $\mathrm{G}_{2}$ show elevated SCE levels only after completing a subsequent replication cycle [24].

Although the molecular mechanisms controlling SCE are not fully understood, HR between sister chromatids is principally responsible for SCE in higher eukaryotic cells [25]. This process is considered to be conservative and error-free, since no information is generally altered during reciprocal interchange by $\mathrm{HR}$. It is known that not all types of DNA damage give rise to SCE. DNA DSB agents can not efficiently induce SCEs. In contrast, SCEs can be induced by various genotoxic treatments causing replication arrest. S phase-dependent agents, such as mitomycin $\mathrm{C}$ (MMC) and UV light are among the most effective inducers of SCE [26], presumably the conditions that increase the cellular burden of SSBs or subsequent DSBs creation during replication stress generally induce SCE efficiently. Thus, the simplest pathway by which SCE likely occurs is through HR-mediated restart of a broken DNA replication fork when it encounters a nick or gap in one parental strand [13] (Figure 2A).

Many HR proteins have been reported to promote SCE in chicken DT40 cells. HR defective mutants, including mutants of RAD51, RAD54, and the RAD51 paralogs (i.e. RAD51B, C, and D and XRCC2), consistently have reduced SCE [25] [27]. However, in mammalian cells, the results are more complex. Rad54 knockout mice cells show little or no reduction in spontaneous SCE, but there is a noticeable deficiency in MMCinduced SCE [28,29]. Moreover, some RAD51 paralog mutants show modest reductions in SCE, but isogenic rad51d mutant lines in both chinese hamster ovary and mouse fibroblasts show no decrease in spontaneous SCE $[29,30]$. Consistent with these studies, we observed that BRCA1 has no obvious role in spontaneous SCE (unpublished data), although BRCA1 promotes replication-stress induced SCE. Although HR is considered to be the pathway for formation of SCEs, the observation that in HR-deficient cells, the background SCE levels are comparable to the parental cells suggests that spontaneous SCEs do not originate from HR. On the contrary, HR seems to be involved in the formation of induced SCEs [31]. In summary, the variation in phenotypes between spontaneous and induced SCE suggests that more than one molecular pathway is responsible for SCE in response to replication stress.

In contrast to HR proteins, several proteins were found to suppress SCE. The helicase protein, BLM, appears to be important in this process since loss of the $B L M$ gives rise to an elevated frequency of SCE during DNA replication [32]. BLM suppresses SCE via multiple processes, including through association with topoisomerase III $\alpha$ (hTOPO III $\alpha$ ) [33-35] and/or RAD51 [36] [37]. It has been suggested BLM and hTOPO III $\alpha$ together effect the resolution of a recombination intermediate containing a double Holliday junction[38]. Although it is believed that BLM works as an anti-recombinase, in Drosophila DmBlm was found to be required specifically to promote the SDSA, a type of HR associated with GC but not cross-over (Figure 1). This result was confirmed in the chicken DT40 B lymphocyte line by demonstrating that Ig GC frequency was drastically reduced in $B L M^{-/-}$cells [39]. Thus, BLM suppresses SCE but promotes GC.

Recent work in our lab showed that ATR suppresses SCE upon replication fork collapse, although ATR has no role in SCE when the replication forks stall [19]. HU, which functions as an inhibitor of ribonucleotide reductase, slows down fork progression by reducing dNTP pools, leading to stalled replication forks that after prolonged treatment collapse into DNA DSBs [14]. We found that ATR depletion leads to an increased rate of SCE in the cells treated with HU for $18 \mathrm{hr}$ when DSBs are efficiently created. Conversely, ATR depletion suppressed I-SceI-induced GC [19]. Although it is not clear how ATR suppresses SCE, there are several possibilities. First, the similar effect of ATR and BLM deficiency on SCE and GC suggest that both proteins act in the same pathway, presumably ATR suppresses SCE via regulation of BLM. BLM is phosphorylated by ATR on two residues, Thr99 and Thr122, and has a role in the recovery from S-phase (16) [40]. Surprisingly expression of BLM containing T99A and T122A substitutions in human BLM defective cells was able to suppress the hyper-SCE 
phenotype, which is the same as expression of wild type BLM, indicating that substitution of Thr99 and Thr122 with alanine did not prevent BLM from suppressing spontaneous SCE [40]. Thus, BLM phosphorylation by ATR has no direct role in spontaneous SCE. However, the possibility that BLM phosphorylation by ATR is important to SCE induced by replication stress has not been tested. Alternatively, the SCE repression by ATR may operate in part by impeding the resection of cutting free DNA ends. It has been reported that the MEC1 replication checkpoint suppresses the formation of RAD52 foci and prevents HR at chromosome breaks induced by the $\mathrm{HO}$ endonuclease in yeast [41]. This repression operates at least in part by impeding resection of DNA ends, which is essential to generate the $3^{\prime}$ ssDNA tails that are the primary substrate of HR. Interestingly, the MEC1 pathway does not prevent recombination at stalled forks, presumably because they already contain ssDNA [41], which is consistent with that the concept that ATR has no role on SCE following replication fork stalling but suppresses SCE following fork collapse after DSBs are produced [19]. Lastly, the elevated SCE frequency following ATR depletion may be related to the specific locations where the increased breakages occur. Chromosomal fragile sites are the regions of the genome which exhibit gaps or breaks on metaphase chromosomes under conditions of partial replication stress [42]. Common fragile sites with or without associated breakages are the preferred location for SCE in aphidicolin treated cultures $[43,44]$. SCEs were found to be distributed nonrandomly across fragile sites and nonfragile sites; and among the fragile sites, the high frequency SCE sites were highly correlated with the high frequency breakage sites [44], indicating that SCE are preferentially induced at common fragile sites with broken ends. ATR protein was found to bind to three regions of FRA3B under conditions of replication stress, and a deficiency of ATR results in a dramatic increase in fragile site breakage $[45,46]$. Thus, defective ATR signaling could result in DNA breakages at the sites which are the hotspots for SCE.

\section{The role of BRCA1 in HR}

Germ line mutations in BRCA1 confer increased susceptibility of developing breast cancer with high penetrance $[47,48]$. BRCA1 function may also be lost in a substantial number of sporadic breast cancers [49-52]. The BRCA1 protein contains multiple functional domains, including a highly conserved $\mathrm{N}$-terminal RING finger which contributes to its E3 ligase activity. BRCA1 interacts directly or indirectly with numerous molecules [53], which is consistent with the observation that BRCA1 deficiency results in pleiotropic phenotypes, including defective DNA damage repair, defective cell cycle checkpoints, increased apoptosis, impaired spindle checkpoint and chromosome damage [54,55]. Although it is not clear if all observed phenotypes contribute to BRCA1 mutations associated tumorigenesis, the function of BRCA1 in HR repair plays a critical role in BRCA1 associated cancer development $[55,56]$.

The observation that BRCA1 associates and colocalizes with RAD51 in nuclear foci in mitotic cells is one of the earliest indications that BRCA1 functions in HR repair [57]. These foci have been observed before and after DNA damage [58-60], indicating the role of BRCA1 in repair of intrinsic or induced DNA damage. Further evidence comes from the observation that BRCA1-deficient cells are highly sensitive to IR and display chromosomal instability including chromatid breaks, a chromosome abbreviation frequently observed in cells with HR deficiency $[61,62]$. There is direct evidence that BRCA1 plays a role in HR. Two reports found that BRCA1 deficiency in mouse embryonic stem cells leads to decreased HR repair of direct DSBs induced by the site-specific I-SceI endonuclease [63,64]. Impaired HR in human cancer cells depleted of BRCA1 using a similar HR reporter has also been observed [65]. In addition there is a report implicating BRCA1 in Ig GC [66]. While the focus of BRCA1 investigation has been on DSB processing, its potential role in dealing with replication stress is relatively less explored. The observation that BRCA1 is required for subnuclear assembly of RAD51 and survival following treatment with a DNA damaging agent that does not cause DNA DSBs suggests that BRCA1 is involved in HR upon replication fork stalling. Our recent work has suggested that both BRCA1 and RAD51 proteins are co-localized with ssDNA regions following $\mathrm{HU}$ treatment for $6 \mathrm{hr}$ when no DSBs is detected. In addition, a reduced proportion of cells with RAD51 foci and SCE frequency were observed in the cells with BRCA1 depletion under the same conditions. This observation suggests a role of BRCA1 in HR via regulation of RAD51 recruitment in the absence of DNA DSBs [19]. This study was the first to shed light on how BRCA1 deficiency influences HR repair in the context of a stalled replication fork. In addition, a recent report by Pathania et al. demonstrated that BRCA1 is important in dealing with UV-induced DNA lesions without detectable DNA DSBs [67]. In the model proposed by the authors, the UV sensitivity of BRCA1-deficient cells may be a compound phenotype from the perturbed intra-S phase and $G 2 / \mathrm{M}$ checkpoints, lesion removal, and TLS. However, given the fact that SCE can be induced by UV light [68] and HR contributes to cell viability after UV-light treatment [69], the role of BRCA1 in SCE at stalled replication forks would be an alternative mechanism contributing to the observed UV sensitivity in BRCA1-deficient cells. In addition to the role in SCE at stalled replication forks, BRCA1 is important for SCE produced by fork collapse as well. However, the role of BRCA1 in replication fork collapse-induced SCE is 
suppressed by ATR whereas the role of BRCA1 in promoting SCE following replication fork stalling is intact with or without ATR depletion. Thus, we conclude that BRCA1 facilitates SCE via distinct mechanisms when replication forks stall or collapse. Interestingly, it has been previously demonstrated that BRCA2-defective hamster cells are impaired in short tract GC but maintain proficiency in SCE [70]. Thus, it would be very interesting to test how BRCA2 regulates SCE when ATR is defective.

The question of why BRCA1 plays a profound role in replication fork collapse-induced SCE in cells with ATR deficiency remains open. One possibility is that SCE rate is very low in the normal context because inappropriate template choice within a sister chromatid leads to unequal SCE leading to gene duplication or deletions, which are associated with tumorigenesis [71]. However, SCE becomes a major mechanism to repair DNA DSBs when cells with a defective checkpoint signaling are challenged by replication stress. Therefore, the role of BRCA1 in SCE-associated HR is not evident unless ATR is depleted. Alternatively, loss of ATR may provide ideal substrates for BRCA1 in HR. BRCA1 promotes repair of DSBs following replication fork collapse via multiple mechanisms whereas BRCA1 promotes HR following replication fork stalling solely via the facilitation of ssDNA resection (see discussion below). Last, ATR may play a direct role in BRCA1dependent SCE following replication fork collapse via phosphorylation of BRCA1. However, it is unclear how ATR-dependent phosphorylation of BRCA1 alters BRCA1 activities in SCE when replication arrests.

Of note, recombination related processes have a central function in the recovery of stalled or collapsed replication forks in both bacteria and eukaryotic cells [10,72]. For example, the endonuclease Mus81 in mammalian cells contributes to replication restart by promoting HR via facilitation of one-ended DSBs generation [12]. However, it was reported recently that HR facilitates repair of DSBs following fork collapse but does not necessarily contribute to replication fork restart in mammalian cells [14]. It was found that stalled replication forks are efficiently restarted in a RAD51-dependent process that does not trigger HR. In contrast, replication fork collapsed by prolonged replication blocks do not restart, and global replication is rescued by new origin firing. Thus, it would be very interesting to evaluate whether the role of BRCA1 in SCE contributes to recovery of stalled/collapsed replication forks.

\section{BRCA1 function in HR: a recombination mediator/ comediator and promoting SsDNA resection}

The interaction of both BRCA1 and BRCA2 with RAD51 suggests a functional link between the three proteins in the RAD51-mediated DNA damage repair process.
However, while BRCA2 is directly involved in RAD51-mediated repair, BRCA1 seems to act in a more complicated mechanism via an interaction with other proteins [73,74] (Figure 1). Although the mechanisms by which BRCA1 functions in HR have not been clear, studies have suggested that BRCA1 acts as a recombination mediator/ comediator, and promotes ssDNA resection via interaction with CtBP-interacting protein (CtIP). Recombination mediators are proteins facilitating displacement of RPA by RAD51 by binding RAD51 and possess a high affinity for ssDNA [5]. The mediators help overcome the suppressive effect of RPA by targeting RAD51 to free DNA or DNA already covered with RPA. To assist these recombination mediators, a second group of proteins is required and we define these proteins here as 'recombination co-mediators' [75]. BRCA2 is a well-defined mediator by direct interaction with RAD51 protein. RAD52 may function as an HR mediator when BRCA2 is absent in mammalian cells [76]. In general, in the absence of mediator/comediator, RAD51 overexpression can partially compensate. BRCA1 might act as a mediator/comediator since overexpression of RAD51 in BRCA1-deficient DT40 cells rescues defects in proliferation, DNA damage survival, and HR support [75,77]. A second molecular mechanism by which BRCA1 acts in HR is via association with CtIP [78]. The work from Yun et al. suggested that the function of CtIP in HR induced by I-SceI overexpression is dependent on BRCA1 recruitment and the phosphorylation of S327, which mediates its interaction with BRCA1 $[79,80]$. Cells expressing CtIP protein that cannot be phosphorylated at S327 are specifically defective in HR and have a decreased level of ssDNA induced by X-rays. The report supports a model in which phosphorylation of CtIP S327 as cells enter S phase, and the recruitment of BRCA1, functions as a molecular switch to shift the balance of DSB repair from error-prone DNA end- joining to error-free HR via facilitating ssDNA resection [78]. The possibility that BRCA1 functions in ssDNA resection via association with CtIP during DNA replication arrest came from our recent publication [19]. We found that CtIP depletion leads to a similar pattern in SCE formation when replication fork arrest compared to those occurring in cells with BRCA1 depletion, namely CtIP knockdown leads to decreased frequency of SCE following replication fork stalling independent of ATR. In contrast, the CtIP knockdown leads to an obviously decreased SCE frequency in cells depleted of ATR after $18 \mathrm{hr}$ HU treatment when obvious DSBs are generated, although it has only a minor effect on SCE formation in cells with intact ATR expression. This result is similar to that observed in cells with BRCA1 knockdown, indicating that CtIP may function in the same pathway as BRCA1 [19].

The questions of whether the molecular mechanism by which BRCA1 promotes SCE after replication fork 
stalling or collapse is similar has not been resolved. However, it appears that BRCA1 may function differentially [19]. We found that BRCA1 depletion leads to a decreased RPA2-phosphorylation by immunoblotting in cells following $6 \mathrm{hr}$ of $\mathrm{HU}$ treatment in the absence of detectable DNA DSBs. Conversely, BRCA1 depletion had no obvious effect on RPA2-phosphorylation in cells following $18 \mathrm{hr}$ of continuous HU treatment. The likely scenario is that loss of BRCA1 leads to a defect in ssDNA resection when replication forks stall, which results in the impaired RPA2-phosphorylation. However, when replication forks collapse, BRCA1 also functions as a mediator of RAD51, and the loss of BRCA1 should lead to increased RPA2-phosphorylation due to a defective RAD51 recruitment, counteracting the decreased RPA2 phosphorylation resulting from impaired ssDNA resection. Thus, the levels of RPA2 phosphorylation are similar in cells with or without BRCA1 depletion when replication forks collapse. The idea that ssDNA resection occurs during replication stalling is supported by evidence from both bacteria and mammalian cells. In E.coli, ssDNA resection is required to enlarge the ssDNA gap for RAD51 dependent HR [81]. Studies in mammalian cells have shown the existence of ssDNA gaps during stalled DNA replication in UV-damaged $S$ phase cells $[82,83]$. RPA-coated ssDNA regions upon UV damage were much reduced in the absence of BRCA1 [67], suggesting a role for BRCA1 in DNA resection when replication forks stall. A model for the role of BRCA1 in HR in response to replication fork stalling or collapse has been proposed in our recent publication [19].

The function of BRCA1 in ssDNA resection is regulated by $53 \mathrm{BP} 1$ and RPA80. The crosstalk between BRCA1 and 53BP1 in ssDNA resection has been highlighted in recent studies. These studies showed that 53BP1 inhibits HR in BRCA1-deficient cells via a blocking resection of DNA breaks [84-86]. Unlike Brca1 mutants, Brca1/53BP1 double mutants are proficient for $\mathrm{HR}$, and assemble RPA foci after DNA damage, arguing that the primary function of BRCA1 in DSB repair is to promote resection by antagonizing 53BP1. These studies also found that loss of 53BP1 restores the deficiency of PARP inhibitor induced SCE in MEF cells with BRCA1 deficiency [84]. Thus, it would be very interesting to determine how 53BP1 affects the role of BRCA1 in SCE formation in response to replication fork stalling or collapse in the future. In addition, a recent study from $\mathrm{Hu}$ et al. suggests that RAP80 contributes to the suppression of exaggerated, BRCA1-dependent HR activity [87]. It was found in this study that the rate of SCE induced by etoposide, a potent DSB inducer, is higher in RAP80depleted cells compared to that observed in control cells. Thus, RAP80/BRCA1 complexes suppress excessive DSB end processing. However, the available data cannot explain how 53BP1 and RAP80 function in the different settings. For instance, the regulation of 53BP1 in ssDNA resection occurs in BRCA1 deficient cells. In contrast, suppressing BRCA1-driven HR by RAP80 can occur in cells with intact BRCA1. Further studies are needed to address these questions.

A very recent publication suggests BRCA1-associated exclusion of 53BP1 from DNA damage sites from examining the spatial distribution of BRCA1 and 53BP1 proteins within single IR induced focus (IRIF) by employing a novel super-resolution microscopy: three dimensional structured illumination microscopy [88]. The authors found that as cells transition through S-phase the recruitment of BRCA1 into the core of IRIF, which they assume involves $\mathrm{HR}$, is associated with an exclusion of $53 \mathrm{BP} 1$ to the focal periphery, leading to an overall reduction in 53BP1-chromatin occupancy. The same pattern was also observed after treatment with camptothecin, a Topoisomerase I inhibitor that induces DSBs in S-phase when replication forks encounter trapped Top1-DNA cleavage complexes. Therefore, the authors propose that BRCA1 antagonizes 53BP1-dependent DNA repair in $\mathrm{S}$-phase by inhibiting its interaction with chromatin proximal to damage sites. How the molecular choreography of $53 \mathrm{BP} 1, \mathrm{BRCA} 1$ and other proteins take place and how this physical distribution in a focus affects the function of BRCA1 in HR, however, is not yet clear.

\section{Is BRCA1 E3 activity required for HR?}

One of the functions of BRCA1 is as an E3 ligase. BRCA1 ubiquitin ligase activity is observed when BRCA1 forms a heterodimeric complex with BARD1 [89]. The potential importance of the E3 ligase activity of BRCA1 in cellular pathways is supported by the observation that missense mutations within RING finger domain of BRCA1, which cause familial breast cancer, abolish the E3 activity [89-93]. The role of BRCA1 E3 activity in HR has been reported in several publications. BRCA1 transgenes with E3 ligase mutations are unable to restore $\mathrm{HR}$ in BRCA1 defective cells using I-SceI based HR reporters detecting GC $[91,94]$. In addition, the investigation of multiple mutants of BRCA1 from patients that disrupt the interaction of E2 enzymes without perturbing the BRCA1-BARD1 complex has revealed that E3 ligase activity strongly correlates with BRCA1 functions in HR, and breast cancer susceptibility [77,94]. Interestingly, many studies have suggested a role for the E3 ligase activity of BRCA1 in HR in repairing two-ended DSBs. However, surprisingly, genetically engineered mouse ES cells expressing BRCA1 with a substitution of alanine for isoleucine at position 26 (I26A), a frequent mutation that disrupts the binding to the E2 subunit without perturbing BARD1 binding [90], do not exhibit HR failure [95]. The ES cells with BRCA1 I26A are resistant to genotoxic stress and are 
capable of accumulating RAD51 at DSBs, and mediate HR repair at the same level as cells with wild type BRCA1. This report questions the importance of E3 ligase activity of BRCA1 to HR. However, the same study also demonstrated that an E3 ligase mutation in BRCA1 leads to a decrease in recombination mediated gene targeting [95]. Since it has been shown that gene targeting occurs through a process in which only a one-ended DSB is involved [96], it is possible that the E3 ligase activity of BRCA1 is only required for HR induced by a one-ended DSB but is not important for HR induced by two-ended DSBs. So it is possible that the E3 ligase activity of BRCA1 is required for the HR process in response to some specific types of DNA damage, such as HR triggered when replication forks are blocked. This hypothesis is supported by the same study demonstrating that the ES cells expressing inactive BRCA1 E3 ligase show an elevated level of damage-induced, but not spontaneous, chromosomal abnormalities [95]. To clarify the mechanisms behind these observations, there is a need to study systematically how E3 ligase activity of BRCA1 regulates HR under replication stress conditions. Any advances in this topic would advance the current knowledge of BRCA1 associated breast cancer development.

\section{The role of BRCA1 in HR in response to replication stress and tumor prevention}

A phenotypic hallmark of cells with mutations in genes involved in HR is chromosome instability. In the absence of HR, the resulting phenotypes can be seen either by spectral karyotyping (SKY) or by array-comparative genomic hybridization (aCGH), which detects large losses and gains across the genome that are common in BRCA1-deficient cells [73]. Genomic instability following loss-of-function of BRCA1 is hypothesized to be a key factor leading to tumorigenesis in individuals with BRCA1 mutations. It is generally believed that BRCA1 maintains genomic stability by promoting error free HR and suppresses error prone NHEJ [97-99]. This idea was further confirmed by a recent report demonstrating that knockdown or loss of the BRCA1 protein results in an increased frequency of plasmid DNA mutagenesis and microhomology mediated end joining following a DSB, suggesting that that BRCA1 protects DNA from mutagenesis during nonhomologous DSB repair [100].

Tumorigenesis due to loss of BRCA1 is a consequence of genetic instability. Numerical and structural aberrations were initially found by SKY analysis in murine embryos carrying a Brca1 null mutation [61]. Later, it was observed that mouse embryonic fibroblast (MEF) cells carrying a targeted deletion of exon 11 display extensive chromosomal abnormalities and a defective $G_{2} / M$ checkpoint [62]. Although the function of BRCA1 in HR was not discussed in the study, chromatid breaks and quadriradial chromosome, two types of featured chromosomal aberrations frequently observed in cells with HR deficiency, were observed in Brcal ${ }^{\Delta 11 / \Delta 11}$ MEFs. The studies from a different group also suggested that spontaneous chromosomal instability, including chromatid breaks and exchanges and chromosome breaks, deletions, and translocations are significantly higher in Brcal $^{-/-}$cells as compared with $\mathrm{Brcal}^{+/+}$[64]. Moreover, dramatic chromosome aberrations were noted in cells deficient in Brca1 [101]. All of the data uncover an essential role of BRCA1 in maintaining genetic stability through numerous functions including HR. Nevertheless, chromosome abnormalities in cells without BRCA1 may not necessarily result from dysfunctions in HR. A recent work from Bunting et al. suggests that BRCA1 functions independently of HR in DNA interstrand crosslink repair [102]. The authors found that Brca1 $1^{\Delta 11 / \Delta 11}$ cells were hypersensitive to two intra- or interstrand crosslinking drugs, nitrogen mustard and MMC. 53BP1 depletion restored HR in Brcal ${ }^{\Delta 11 / \Delta 11}$ cells but did not restore the sensitivity and chromosome aberrations including chromosome and chromatid breaks and radiation structures, indicating that BRCA1 has a function in crosslink repair and maintaining genomic stability during replication arrest which is separate from its role in HR.

\section{Loss of genes required for cell cycle checkpoints and BRCA1 associated tumorigenesis}

Cells with damaged DNA frequently arrest, which reduces the probability of progressing to malignancy. Mutations in checkpoint pathways can permit the survival or continued growth of cells with genomic abnormalities, thus enhancing the likelihood of malignant transformation [103]. This is no exception for BRCA1 mutation associated tumor development. Loss of BRCA1 leads to embryonic lethality. Multiple studies suggest that the p53 loss cooperates with the loss of BRCA1 in tumorigenesis [61,104109]. In addition, other genes required for cell cycle checkpoint, including ATM, CHK2 and ATR, seem to be important also for BRCA1-mutation tumorigenesis. Loss of Atm or Chk2 rescues the embryonic lethality of Brca1 mutant mice and leads to the development of multiple tumors [110]. In addition, ATM expression can be aberrantly reduced or lost in tumors expressing BRCA1 or BRCA2 mutants compared with sporadic tumors without BRCA1 or BRCA2 mutations [111]. Epidemiological evidence implicates that Chk2 and BRCA1 are in the same breast cancer prevention pathway [112], which is supported by the molecular process controlled by their interaction. Chk2 phosphorylates the serine 988 (S988) residue of BRCA1 and co-localizes with BRCA1 within discrete nuclear foci prior to DNA damage by $\gamma$-irradiation [113]. This phosphorylation is critical for the ability of BRCA1 to restore survival after DNA damage in BRCA1-mutated 
cell lines. In addition, the studies from our lab and others show that prevention of Chk2-mediated phosphorylation via mutation of the S988 of BRCA1 disrupts both HR detected by I-SceI reporter and the suppression of error prone-NHEJ [97-99], supporting the hypothesis that Chk2-dependent phosphorylation modulates the function of BRCA1 [97,99]. Moreover, uterus hyperplasia and increased carcinogen-induced tumorigenesis in mice carrying a targeted mutation of the Chk2 phosphorylation site in BRCA1 has been reported [114], suggesting that Chk2 phosphorylation is involved in the BRCA1 function in repressing tumor formation. An interesting question would be whether the role of BRCA1 in SCE induced by replication arrest is regulated by Chk2 phosphorylation.

ATR signaling regulates several cell cycle checkpoints and induces S-phase arrest in response to replication stresses [115]. Although there is no data available for the role of ATR in BRCA1 associated tumorigenesis in animal models, a linkage of ATR with BRCA1 was suggested by earlier cell biology and biochemistry studies. ATR can phosphorylate BRCA1 on several residues [116-118]. Moreover, ATR colocalizes with BRCA1 in foci in cells synchronized in $\mathrm{S}$ phase and after exposure to DNA damaging agents or DNA replication inhibitors, associating BRCA1 and ATR with the response to stalled replication forks $[117,118]$. Furthermore, the dramatic relocalization of ATR nuclear foci in response to DNA damage overlaps with the nuclear foci formed by BRCA1. In addition to cell biology and biochemistry studies, it has been reported that ATR was down-regulated in BRCA1 mutation carriers following radiation using high-density cDNA microarray technology [119]. In this study, the expression profiles of breast fibroblast samples from nine heterozygous BRCA1 mutant carrier individuals were compared to the profiles of five reduction mammoplasty fibroblast samples with a very low probability of the presence of BRCA1 mutations as controls. All of the samples were short-term primary cultures, and were irradiated to induce sublethal DNA damage. ATR was found to be down-regulated in mutation carriers compared with the controls, indicating a potential role of BRCA1 in ATR expression because of its decreased transcription [119], and further suggesting that ATR may be involved in BRCA1 associated tumorigenesis. Since the function of BRCA1 in SCE following replication fork collapse is more profound when ATR is depleted, this could be another molecular mechanism explaining why a second mutation in cell cycle checkpoint genes is important for BRCA1 associated cancer development in addition to permitting survival of the cells with BRCA1 mutations.

\section{The role of BRCA1 in HR following replication stress: implications in PARP-inhibitor therapy}

PARP inhibitors have been shown to be selectively lethal to cells deficient in BRCA1 or BRCA2 due to synthetic lethality [120-123]. The PARP family consists of 17 proteins based on structural similarity. PARP1 is the protein that is best understood. This protein detects and binds to sites of ssDNA damage, and then synthesizes poly (ADP) ribose (pADPr, PAR) and transfers it to acceptor proteins. The acceptor proteins include PARP1 itself and other proteins involved in DNA repair, such as XRCC1, a protein involved in BER [124]. However, a recent report from Ström et al. suggested a distinct role of XRCC1 and PARP inhibition in SSB repair [125]. No direct role for PARP1 in BER was observed, but that PARP inhibitors trap PARP on the SSB intermediate formed during BER. Therefore, PARP1 plays an essential role in the latter steps of BER ligation. It is widely believed that the reason that recombination defective cells are sensitive to PARP inhibitors is because GC-associated $\mathrm{HR}$ has an important role in repairing a DSB. Thus, the increased number of unrepaired endogenous SSBs in PARP inhibited cells result in more collapsed replication forks, which require GCmediated HR for repair [126]. In a BRCA1/2 defective background these DSBs are likely to be repaired by more error-prone repair mechanisms, causing chromosome aberrations and loss of viability [54]. However, the observations that SCE but not GC is the most frequent HR occurring during replication stress suggest that SCE may be more critical for repairing PARP1 inhibition associated lesions. In addition, the results from Schultz et al. suggest that GC following induction of a site-specific DSB is normal in PARP1-inhibited cells. In contrast, PARP1 inhibition leads to an increase in crossovers as measured by SCE frequency in culture [127]. Cells isolated from PARP1 knockout mice exhibit a hyper recombination phenotype and genetic instability in the form of increased levels of SCE, micronuclei and tetraploidy [128,129]. Moreover, the study from Bunting et al. also demonstrated that PARP inhibition caused an increased SCE in MEF cells [84]. All of these studies suggest that SCE is involved in repairing DNA lesions caused by PARP inhibition. BRCA1 promotes SCE-mediated HR in response to replication stress, which could be a mechanism explaining why BRCA1 deficient cells is hypersensitive to PARP inhibitors. Therefore, it is most likely that without PARP1, SSBs accumulate and then collapse replication forks to initiate SCE-mediated HR. If a PARP1 deficient cell is also deficient in BRCA1, SCE-mediated HR cannot occur, and the cell then dies or undergoes error-prone NHEJ (Figure 3). However, the possibility that the role of BRCA1 in GC is important for cell killing induced by PARP inhibitors cannot be excluded. In addition, it is also important to recognize that PARP activity and other proteins are also important for HR at stalled forks since it has been recently reported that PARP1 collaborates with MRE11 to promote replication fork restart, most likely by recruiting MRE11 to the replication fork to promote 


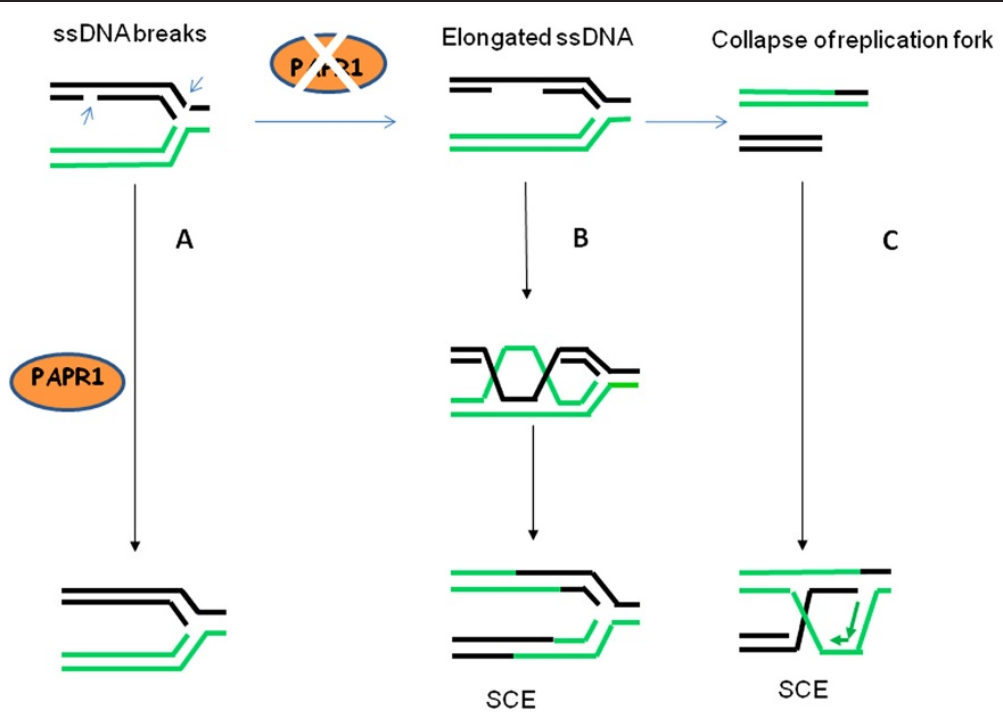

Figure 3 DNA lesions caused by PARP inhibitors lead to increased crossovers. DNA breaks are detected by PARP1 and PARP1 is active in response to DNA breaks. In the cells with intact PARP1 activity, the sSDNA is efficiently repaired (A). However, when the PARP1 activity is inhibited, unrepaired ssDNA breaks can be converted into elongated ssDNA (B) or subsequently into DSBs due to replication collapse (C). Both DNA structures stimulate SCE via HR.

resection of DNA. Both PARP1 and PARP2 are required for HU-induced HR and cell survival after replication blocks [130].

\section{PARP1 resistance}

Although PARP inhibitors displayed promising results for killing cancer cells with BRCA1/BRCA2 deficiency, there are several issues regarding PARP inhibitor-related therapies. Like other chemotherapy, acquired resistance to PARP inhibitors has been reported. The resistance to PARP inhibitors has led to the failure of phase III clinical trials in triple negative breast cancers[131]. Thus, there is urgency for elucidating the mechanisms by which resistance occurs. The acquired resistance to PARP inhibitors may be due to various mechanisms, including reverting inherited mutations in BRCA2 [132,133], an up-regulation of the $A b c b 1 a / b$ gene encoding a P-glycoprotein efflux pump [134], and loss of 53BP1 which leads to restoration of impaired ssDNA resection resulting from BRCA1 deficiency [84]. In support of the idea that SCE-associated HR is required for repairing the DNA lesions caused by PARP inhibitors, 53BP1 depletion restores the decreased frequency of SCE because of BRCA1 deficiency [84]. How to overcome the acquired resistance to PARP inhibitors is a new direction for future study; strategies to overcome acquired resistance to PARP inhibitors has been discussed in review [124]. For instance, it has been reported that 6-thioguanine selectively kills BRCA2-defective tumors and overcomes PARP inhibitor resistance [135].
A second issue regarding PARP inhibitor associated therapy is that even if there is an observed sensitivity to PARP inhibitors in cancer cells without functional BRCA1, the difference is much smaller compared with the difference reported previously on pre-cancerous cells [136]. In addition, not all breast cancer patients with BRCA1 mutations respond to PARP inhibitors [137] and a substantial fraction of advanced BRCA1-mutant cancers are resistant to these agents. Therefore, the potential factor(s) contributing the effectiveness of PARP inhibitors in the cytotoxicity of breast cancer cells with mutant BRCA1 needs to be explored. Since SCE mediated HR appears to be important to repair PARP inhibitor-induced replication lesions, any factors which potentially regulate SCE should have an effect on PARP inhibitor-associated cancer treatment. The observation that the role of BRCA1 in promotion of SCE following replication fork collapse is more profound in cells depleted of ATR provides the possibility of sensitizing cancer cells without functional of BRCA1 to PARP inhibitors by ATR inhibitors. Thus, the status of cell cycle checkpoints should be taken into account when PARP inhibitors are applied.

\section{Conclusions and perspectives}

Mitotic HR promotes genome stability through the precise repair of DNA DSBs and other lesions that are encountered during normal cellular DNA replication and replication stress. Deficiency in HR provides a promising target for cancer therapy. It has become apparent that HR repair produced by replication arrest is different to 
that required for repairing classical two-ended DSBs. In the past, research has been focused on the role of BRCA1 in classical two ended DNA DSB repair by HR. Recent studies suggest that BRCA1 is critical for several subtype HR pathways following replication arrest. However, how BRCA1 acts in HR when replication forks stall/collapse has not yet been satisfactorily answered. Hence, further studies are needed to focus on the regulatory mechanisms of HR repair by BRCA1 in response to DNA replication stress in different settings. Any advance regarding this topic will benefit our understanding of the mechanisms underlying BRCA1 associated tumorigenesis, as well as the development of therapeutic approaches for cancer patients with dysfunctional BRCA1.

\section{Abbreviations \\ PARP: Poly(ADP-ribose) polymerase; DSBs: DNA double strand breaks; DSBR: Double-strand break repair; SDSA: Synthesis-dependent strand annealing; IR: lonizing radiation; BER: Base excision repair; NER: Nucleic acid excision repair; HR: Homologous recombination; SSA: Single strand annealing; MMR: Mismatch repair; NHEJ: Non-homologous end joining; ssDNA: Single stranded DNA; HJ: Holliday junction; GC: Gene conversion; SCE: Sister chromatid exchange; IRIF: IR induced focus; MMC: Mitomycin C; HU: Hydroxyurea; TLS: Translesion DNA synthesis; aCGH: Array-comparative genomic hybridization; MEF: Mouse embryonic fibroblast cells; SKY: Spectral karyotyping.}

\section{Competing interests}

The author declares no competing financial interests.

\section{Authors' contributions}

JZ drafted the manuscript and approved the final manuscript.

\section{Authors' information}

$\mathrm{JZ}$ is currently an assistant professor in the Department of Radiation Oncology, Case Western Reserve University School of Medicine. JZ has more than ten years of experience in homologous recombination.

\section{Acknowledgements}

I would like to thank Dr. Thomas Helleday for the critical reading of this manuscript and helpful comments. I also thank Dr. Scott Welford for the assistance in editing. I apologize to colleagues whose work was not cited due to space limitations or my ignorance.

Research in my laboratory is supported by American Cancer Society (IRG-58-010-51) and National Cancer Institute (grant R01CA154625) and a startup fund from the Department of Radiation Oncology, Case Western Reserve University School of Medicine (to J.Z).

Received: 20 August 2012 Accepted: 20 December 2012 Published: 6 February 2013

\section{References}

1. Hoeijmakers JH: Genome maintenance mechanisms for preventing cancer. Nature 2001, 411(6835):366-374.

2. Borde $\mathrm{V}$ : The multiple roles of the Mre11 complex for meiotic recombination. Chromosome Res 2007, 15(5):551-563.

3. Assenmacher N, Hopfner KP: MRE11/RAD50/NBS1: complex activities. Chromosoma 2004, 113(4):157-166.

4. Sartori AA, Lukas C, Coates J, Mistrik M, Fu S, Bartek J, Baer R, Lukas J, Jackson SP: Human CtIP promotes DNA end resection. Nature 2007, 450(7169):509-514.

5. Sung P, Krejci L, Van Komen S, Sehorn MG: Rad51 recombinase and recombination mediators. J Biol Chem 2003, 278(44):42729-42732.

6. Sung P, Klein H: Mechanism of homologous recombination: mediators and helicases take on regulatory functions. Nat Rev Mol Cell Biol 2006, 7(10):739-750
7. Liu Y, West SC: Happy Hollidays: 40th anniversary of the Holliday junction. Nat Rev Mol Cell Biol 2004, 5(11):937-944.

8. Liu Y, Masson JY, Shah R, O'Regan P, West SC: RAD51C is required for Holliday junction processing in mammalian cells. Science 2004, 303(5655):243-246.

9. Alberts B: Molecular biology of the cell. 5th edition. New York: Garland Science; 2008.

10. Heller RC, Marians K: Replisome assembly and the direct restart of stalled replication forks. Nat Rev Mol Cell Biol 2006, 7(12):932-943.

11. Hanada K, Budzowska M, Modesti M, Maas A, Wyman C, Essers J, Kanaar R: The structure-specific endonuclease Mus81-Eme1 promotes conversion of interstrand DNA crosslinks into double-strands breaks. EMBO J 2006, 25(20):4921-4932.

12. Hanada K, Budzowska M, Davies SL, van Drunen E, Onizawa H, Beverloo HB, Maas A, Essers J, Hickson ID, Kanaar R: The structure-specific endonuclease Mus81 contributes to replication restart by generating double-strand DNA breaks. Nat Struct Mol Biol 2007, 14(11):1096-1104.

13. Wilson DM 3rd, Thompson LH: Molecular mechanisms of sister-chromatid exchange. Mutat Res 2007, 616(1-2):11-23.

14. Petermann E, Orta ML, Issaeva N, Schultz N, Helleday T: Hydroxyurea-stalled replication forks become progressively inactivated and require two different RAD51-mediated pathways for restart and repair. Mol Cell 2010, 37(4):492-502.

15. Wyman C, Kanaar R: DNA double-strand break repair: all's well that ends well. Annu Rev Genet 2006, 40:363-383.

16. Elvers I, Johansson F, Groth P, Erixon K, Helleday T: UV stalled replication forks restart by re-priming in human fibroblasts. Nucleic Acids Res 2011, 39(16):7049-7057.

17. Saintigny Y, Delacote F, Vares G, Petitot F, Lambert S, Averbeck D, Lopez BS: Characterization of homologous recombination induced by replication inhibition in mammalian cells. EMBO J 2001, 20(14):3861-3870.

18. Lundin C, Erixon K, Arnaudeau C, Schultz N, Jenssen D, Meuth M, Helleday $\mathrm{T}$ : Different roles for nonhomologous end joining and homologous recombination following replication arrest in mammalian cells. Mol Cell Biol 2002, 22(16):5869-5878.

19. Feng Z, Zhang J: A dual role of BRCA1 in two distinct homologous recombination mediated repair in response to replication arrest. Nucleic Acids Res 2012, 40(2):726-738.

20. Johnson RD, Jasin M: Sister chromatid gene conversion is a prominent double-strand break repair pathway in mammalian cells. EMBO J 2000, 19(13):3398-3407.

21. Arnaudeau C, Lundin C, Helleday T: DNA double-strand breaks associated with replication forks are predominantly repaired by homologous recombination involving an exchange mechanism in mammalian cells. J Mol Biol 2001, 307(5):1235-1245.

22. Saleh-Gohari N, Bryant HE, Schultz N, Parker KM, Cassel TN, Helleday T: Spontaneous homologous recombination is induced by collapsed replication forks that are caused by endogenous DNA single-strand breaks. Mol Cell Biol 2005, 25(16):7158-7169.

23. Shi W, Feng Z, Zhang J, Gonzalez-Suarez I, Vanderwaal RP, Wu X, Powell SN, Roti Roti JL, Gonzalo S, Zhang J: The Role of RPA2 Phosphorylation in Homologous Recombination in Response to Replication Arrest. Carcinogenesis 2010, 31(6):994-1002.

24. Wolff S, Bodycote J, Painter RB: Sister chromatid exchanges induced in Chinese hamster cells by UV irradiation of different stages of the cell cycle: the necessity for cells to pass through S. Mutat Res 1974, 25(1):73-81.

25. Sonoda E, Sasaki MS, Morrison C, Yamaguchi-Iwai Y, Takata M, Takeda S: Sister chromatid exchanges are mediated by homologous recombination in vertebrate cells. Mol Cell Biol 1999, 19(7):5166-5169.

26. Latt SA: Sister chromatid exchange formation. Annu Rev Genet 1981, 15:11-55.

27. Takata M, Sasaki MS, Tachiiri S, Fukushima T, Sonoda E, Schild D, Thompson $L H$, Takeda S: Chromosome instability and defective recombinational repair in knockout mutants of the five Rad51 paralogs. Mol Cell Biol 2001, 21(8):2858-2866.

28. Dronkert ML, Beverloo HB, Johnson RD, Hoeijmakers JH, Jasin M, Kanaar R: Mouse RAD54 affects DNA double-strand break repair and sister chromatid exchange. Mol Cell Biol 2000, 20(9):3147-3156.

29. Smiraldo PG, Gruver AM, Osborn JC, Pittman DL: Extensive chromosomal instability in Rad51d-deficient mouse cells. Cancer Res 2005, 65(6):2089-2096. 
30. Hinz JM, Tebbs RS, Wilson PF, Nham PB, Salazar EP, Nagasawa H, Urbin SS, Bedford JS, Thompson LH: Repression of mutagenesis by Rad51Dmediated homologous recombination. Nucleic Acids Res 2006, 34(5):1358-1368.

31. Natarajan AT, Palitti F: DNA repair and chromosomal alterations. Mutat Res 2008, 657(1):3-7

32. Chaganti RS, Schonberg S, German J: A manyfold increase in sister chromatid exchanges in Bloom's syndrome lymphocytes. Proc Natl Acad Sci U S A 1974, 71(11):4508-4512.

33. Wu L, Davies SL, North PS, Goulaouic H, Riou JF, Turley H, Gatter KC, Hickson ID: The Bloom's syndrome gene product interacts with topoisomerase III. J Biol Chem 2000, 275(13):9636-9644.

34. Johnson FB, Lombard DB, Neff NF, Mastrangelo MA, Dewolf W, Ellis NA, Marciniak RA, Yin Y, Jaenisch R, Guarente L: Association of the Bloom syndrome protein with topoisomerase Illalpha in somatic and meiotic cells. Cancer Res 2000, 60(5):1162-1167.

35. Wu L, Hickson ID: RecQ helicases and topoisomerases: components of a conserved complex for the regulation of genetic recombination. Cell Mol Life Sci 2001, 58(7):894-901.

36. Wu L, Davies SL, Levitt NC, Hickson ID: Potential role for the BLM helicase in recombinational repair via a conserved interaction with RAD51. J Biol Chem 2001, 276(22):19375-19381.

37. Karow JK, Constantinou A, Li JL, West SC, Hickson ID: The Bloom's syndrome gene product promotes branch migration of holliday junctions. Proc Natl Acad Sci U S A 2000, 97(12):6504-6508.

38. Wu L, Hickson ID: The Bloom's syndrome helicase suppresses crossing over during homologous recombination. Nature 2003, 426(6968):870-874.

39. Kikuchi K, Abdel-Aziz HI, Taniguchi Y, Yamazoe M, Takeda S, Hirota K: Bloom DNA helicase facilitates homologous recombination between diverged homologous sequences. J Biol Chem 2009, 284(39):26360-26367.

40. Davies SL, North PS, Dart A, Lakin ND, Hickson ID: Phosphorylation of the Bloom's syndrome helicase and its role in recovery from S-phase arrest. Mol Cell Biol 2004, 24(3):1279-1291.

41. Alabert C, Bianco JN, Pasero P: Differential regulation of homologous recombination at DNA breaks and replication forks by the Mrc1 branch of the S-phase checkpoint. EMBO J 2009, 28(8):1131-1141.

42. Richards Rl: Fragile and unstable chromosomes in cancer: causes and consequences. Trends in genetics: TIG 2001, 17(6):339-345.

43. Glover TW, Stein CK: Induction of sister chromatid exchanges at common fragile sites. Am J Hum Genet 1987, 41(5):882-890.

44. Hirsch B: Sister chromatid exchanges are preferentially induced at expressed and nonexpressed common fragile sites. Hum Genet 1991, 87(3):302-306

45. Casper AM, Nghiem P, Arlt MF, Glover TW: ATR regulates fragile site stability. Cell 2002, 111(6):779-789.

46. Casper AM, Durkin SG, Arlt MF, Glover TW: Chromosomal instability at common fragile sites in Seckel syndrome. Am J Hum Genet 2004, 75(4):654-660.

47. Narod SA, Foulkes WD: BRCA1 and BRCA2: 1994 and beyond. Nat Rev Cancer 2004, 4(9):665-676.

48. Antoniou A, Pharoah PD, Narod S, Risch HA, Eyfjord JE, Hopper JL, Loman N, Olsson $\mathrm{H}$, Johannsson $\mathrm{O}$, Borg $\mathrm{A}$, et al: Average risks of breast and ovarian cancer associated with BRCA1 or BRCA2 mutations detected in case Series unselected for family history: a combined analysis of 22 studies. Am J Hum Genet 2003, 72(5):1117-1130.

49. Esteller M, Silva JM, Dominguez G, Bonilla F, Matias-Guiu X, Lerma E, Bussaglia E, Prat J, Harkes IC, Repasky EA, et al: Promoter hypermethylation and BRCA1 inactivation in sporadic breast and ovarian tumors. J Natl Cancer Inst 2000, 92(7):564-569.

50. Russell PA, Pharoah PD, De Foy K, Ramus SJ, Symmonds I, Wilson A, Scott I, Ponder BA, Gayther SA: Frequent loss of BRCA1 mRNA and protein expression in sporadic ovarian cancers. International journal of cancer Journal international du cancer 2000, 87(3):317-321

51. Thompson ME, Jensen RA, Obermiller PS, Page DL, Holt JT: Decreased expression of BRCA1 accelerates growth and is often present during sporadic breast cancer progression. Nat Genet 1995, 9(4):444-450.

52. Wilson CA, Ramos L, Villasenor MR, Anders KH, Press MF, Clarke K, Karlan B, Chen JJ, Scully R, Livingston D, et al: Localization of human BRCA1 and its loss in high-grade, non-inherited breast carcinomas. Nat Genet 1999 21(2):236-240
53. Deng CX, Brodie SG: Roles of BRCA1 and its interacting proteins. BioEssays: news and reviews in molecular, cellular and developmental biology 2000, 22(8):728-737.

54. Gudmundsdottir K, Ashworth A: The roles of BRCA1 and BRCA2 and associated proteins in the maintenance of genomic stability. Oncogene 2006, 25(43):5864-5874.

55. Moynahan ME, Jasin M: Mitotic homologous recombination maintains genomic stability and suppresses tumorigenesis. Nat Rev Mol Cell Biol 2010, 11(3):196-207.

56. Helleday T: Homologous recombination in cancer development, treatment and development of drug resistance. Carcinogenesis 2010 31(6):955-960.

57. Scully R, Chen J, Plug A, Xiao Y, Weaver D, Feunteun J, Ashley T, Livingston DM: Association of BRCA1 with Rad51 in mitotic and meiotic cells. Cell 1997, 88(2):265-275.

58. Jin Y, Xu XL, Yang MC, Wei F, Ayi TC, Bowcock AM, Baer R: Cell cycledependent colocalization of BARD1 and BRCA1 proteins in discrete nuclear domains. Proc Natl Acad Sci U S A 1997, 94(22):12075-12080.

59. Scully R, Chen J, Ochs RL, Keegan K, Hoekstra M, Feunteun J, Livingston DM: Dynamic changes of BRCA1 subnuclear location and phosphorylation state are initiated by DNA damage. Cell 1997, 90(3):425-435.

60. Chen J, Silver DP, Walpita D, Cantor SB, Gazdar AF, Tomlinson G, Couch FJ, Weber BL, Ashley T, Livingston DM, et al: Stable interaction between the products of the BRCA1 and BRCA2 tumor suppressor genes in mitotic and meiotic cells. Mol Cell 1998, 2(3):317-328.

61. Shen SX, Weaver Z, Xu X, Li C, Weinstein M, Chen L, Guan XY, Ried T, Deng CX: A targeted disruption of the murine Brcal gene causes gamma-irradiation hypersensitivity and genetic instability. Oncogene 1998, 17(24):3115-3124.

62. Xu X, Weaver Z, Linke SP, Li C, Gotay J, Wang XW, Harris CC, Ried T, Deng CX: Centrosome amplification and a defective G2-M cell cycle checkpoint induce genetic instability in BRCA1 exon 11 isoform-deficient cells. Mol Cell 1999, 3(3):389-395.

63. Moynahan ME, Chiu JW, Koller BH, Jasin M: Brca1 controls homologydirected DNA repair. Mol Cell 1999, 4(4):511-518.

64. Moynahan ME, Cui TY, Jasin M: Homology-directed dna repair, mitomycinc resistance, and chromosome stability is restored with correction of a Brca1 mutation. Cancer Res 2001, 61(12):4842-4850.

65. Zhang J, Ma Z, Treszezamsky A, Powell SN: MDC1 interacts with Rad51 and facilitates homologous recombination. Nat Struct Mol Biol 2005, 12(10):902-909.

66. Longerich S, Orelli BJ, Martin RW, Bishop DK, Storb U: Brca1 in immunoglobulin gene conversion and somatic hypermutation. DNA Repair 2008, 7(2):253-266.

67. Pathania S, Nguyen J, Hill SJ, Scully R, Adelmant GO, Marto JA, Feunteun J, Livingston DM: BRCA1 is required for postreplication repair after UVinduced DNA damage. Mol Cell 2011, 44(2):235-251.

68. Kato H: Induction of sister chromatid exchanges by UV light and its inhibition by caffeine. Exp Cell Res 1973, 82(2):383-390.

69. Eppink B, Tafel AA, Hanada K, van Drunen E, Hickson ID, Essers J, Kanaar R: The response of mammalian cells to UV-light reveals Rad54-dependent and independent pathways of homologous recombination. DNA Repair 2011, 10(11):1095-1105.

70. Saleh-Gohari N, Helleday T: Strand invasion involving short tract gene conversion is specifically suppressed in BRCA2-deficient hamster cells Oncogene 2004, 23(56):9136-9141.

71. Kasparek TR, Humphrey TC: DNA double-strand break repair pathways, chromosomal rearrangements and cancer. Semin Cell Dev Biol 2011, 22(8):886-897

72. Petermann E, Helleday T: Pathways of mammalian replication fork restart. Nat Rev Mol Cell Biol 2010, 11(10):683-687.

73. Roy R, Chun J, Powell SN: BRCA1 and BRCA2: different roles in a common pathway of genome protection. Nat Rev Cancer 2012, 12(1):68-78.

74. Liu Y, West SC: Distinct functions of BRCA1 and BRCA2 in double-strand break repair. Breast cancer research: BCR 2002, 4(1):9-13.

75. Schild D, Wiese C: Overexpression of RAD51 suppresses recombination defects: a possible mechanism to reverse genomic instability. Nucleic Acids Res 2010, 38(4):1061-1070.

76. Feng Z, Scott SP, Bussen W, Sharma GG, Guo G, Pandita TK, Powell SN: Rad52 inactivation is synthetically lethal with BRCA2 deficiency. Proc Natl Acad Sci U S A 2011, 108(2):686-691. 
77. Martin RW, Orelli BJ, Yamazoe M, Minn AJ, Takeda S, Bishop DK: RAD51 upregulation bypasses $B R C A 1$ function and is a common feature of BRCA1deficient breast tumors. Cancer Res 2007, 67(20):9658-9665.

78. Yun MH, Hiom K: CtIP-BRCA1 modulates the choice of DNA doublestrand-break repair pathway throughout the cell cycle. Nature 2009, 459(7245):460-463

79. Yu X, Chen J: DNA damage-induced cell cycle checkpoint control requires CtIP, a phosphorylation-dependent binding partner of BRCA1 Cterminal domains. Mol Cell Biol 2004, 24(21):9478-9486.

80. Greenberg RA, Sobhian B, Pathania S, Cantor SB, Nakatani Y, Livingston DM: Multifactorial contributions to an acute DNA damage response by BRCA1/BARD1-containing complexes. Genes Dev 2006, 20(1):34-46.

81. Michel B, Boubakri H, Baharoglu Z, LeMasson M, Lestini R: Recombination proteins and rescue of arrested replication forks. DNA Repair 2007, 6(7):967-980.

82. Byun TS, Pacek M, Yee MC, Walter JC, Cimprich KA: Functional uncoupling of MCM helicase and DNA polymerase activities activates the ATRdependent checkpoint. Genes Dev 2005, 19(9):1040-1052.

83. Cortez D: Unwind and slow down: checkpoint activation by helicase and polymerase uncoupling. Genes Dev 2005, 19(9):1007-1012.

84. Bunting SF, Callen E, Wong N, Chen HT, Polato F, Gunn A, Bothmer A, Feldhahn N, Fernandez-Capetillo O, Cao L, et al: 53BP1 inhibits homologous recombination in Brca1-deficient cells by blocking resection of DNA breaks. Cell 2010, 141(2):243-254.

85. Cao L, Xu X, Bunting SF, Liu J, Wang RH, Cao LL, Wu JJ, Peng TN, Chen J, Nussenzweig A, et al: A selective requirement for 53BP1 in the biological response to genomic instability induced by Brca1 deficiency. Mol Cell 2009, 35(4):534-541.

86. Bouwman P, Aly A, Escandell JM, Pieterse M, Bartkova J, van der Gulden H, Hiddingh S, Thanasoula M, Kulkarni A, Yang Q, et al: 53BP1 loss rescues BRCA1 deficiency and is associated with triple-negative and BRCAmutated breast cancers. Nat Struct Mol Biol 2010, 17(6):688-695.

87. Hu Y, Scully R, Sobhian B, Xie A, Shestakova E, Livingston DM: RAP80directed tuning of BRCA1 homologous recombination function at ionizing radiation-induced nuclear foci. Genes Dev 2011, 25(7):685-700.

88. Chapman JR, Sossick AJ, Boulton SJ, Jackson SP: BRCA1-associated exclusion of 53BP1 from DNA damage sites underlies temporal control of DNA repair. J Cell Sci 2012, 125(Pt 15):3529-3534.

89. Hashizume R, Fukuda M, Maeda I, Nishikawa H, Oyake D, Yabuki Y, Ogata $H_{\text {, }}$ Ohta T: The RING heterodimer BRCA1-BARD1 is a ubiquitin ligase inactivated by a breast cancer-derived mutation. J Biol Chem 2001, 276(18):14537-14540.

90. Brzovic PS, Keeffe JR, Nishikawa H, Miyamoto K, Fox D 3rd, Fukuda M, Ohta T, Klevit R: Binding and recognition in the assembly of an active BRCA1/ BARD1 ubiquitin-ligase complex. Proc Natl Acad Sci U S A 2003, 100(10):5646-5651

91. Ruffner $H$, Joazeiro CA, Hemmati D, Hunter T, Verma IM: Cancerpredisposing mutations within the RING domain of BRCA1: loss of ubiquitin protein ligase activity and protection from radiation hypersensitivity. Proc Natl Acad Sci U S A 2001, 98(9):5134-5139.

92. Couch FJ, Weber BL: Mutations and polymorphisms in the familial earlyonset breast cancer (BRCA1) gene, Breast Cancer Information Core. Hum Mutat 1996, 8(1):8-18.

93. Shattuck-Eidens D, McClure M, Simard J, Labrie F, Narod S, Couch F, Hoskins K, Weber B, Castilla L, Erdos M, et al: A collaborative survey of 80 mutations in the BRCA1 breast and ovarian cancer susceptibility gene. Implications for presymptomatic testing and screening. JAMA: the journal of the American Medical Association 1995, 273(7):535-541.

94. Ransburgh DJ, Chiba N, Ishioka C, Toland AE, Parvin JD: Identification of breast tumor mutations in BRCA1 that abolish its function in homologous DNA recombination. Cancer Res 2010, 70(3):988-995.

95. Reid LJ, Shakya R, Modi AP, Lokshin M, Cheng JT, Jasin M, Baer R, Ludwig T: E3 ligase activity of BRCA1 is not essential for mammalian cell viability or homology-directed repair of double-strand DNA breaks. Proc Natl Acad Sci U S A 2008, 105(52):20876-20881.

96. Pierce AJ, Hu P, Han M, Ellis N, Jasin M: Ku DNA end-binding protein modulates homologous repair of double-strand breaks in mammalian cells. Genes Dev 2001, 15(24):3237-3242.

97. Zhuang J, Zhang J, Willers H, Wang H, Chung JH, van Gent DC, Hallahan DE, Powell SN, Xia F: Checkpoint kinase 2-mediated phosphorylation of BRCA1 regulates the fidelity of nonhomologous end-joining. Cancer Res 2006, 66(3):1401-1408
98. Wang HC, Chou WC, Shieh SY, Shen CY: Ataxia telangiectasia mutated and checkpoint kinase 2 regulate BRCA1 to promote the fidelity of DNA endjoining. Cancer Res 2006, 66(3):1391-1400

99. Zhang J, Willers H, Feng Z, Ghosh JC, Kim S, Weaver DT, Chung JH, Powel $\mathrm{SN}$, Xia F: Chk2 phosphorylation of BRCA1 regulates DNA double-strand break repair. Mol Cell Biol 2004, 24(2):708-718.

100. Thompson EG, Fares $H$, Dixon K: BRCA1 requirement for the fidelity of plasmid DNA double-strand break repair in cultured breast epithelial cells. Environ Mol Mutagen 2012, 53(1):32-43.

101. Turner BC, Ottey M, Zimonjic DB, Potoczek M, Hauck WW, Pequignot E Keck-Waggoner CL, Sevignani C, Aldaz CM, McCue PA, et al: The fragile histidine triad/common chromosome fragile site $3 \mathrm{~B}$ locus and repairdeficient cancers. Cancer Res 2002, 62(14):4054-4060.

102. Bunting SF, Callen E, Kozak ML, Kim JM, Wong N, Lopez-Contreras AJ, Ludwig T, Baer R, Faryabi RB, Malhowski A, et al: BRCA1 functions independently of homologous recombination in DNA interstrand crosslink repair. Mol Cell 2012, 46(2):125-135.

103. Kastan MB, Bartek J: Cell-cycle checkpoints and cancer. Nature 2004, 432(7015):316-323

104. Cressman VL, Backlund DC, Avrutskaya AV, Leadon SA, Godfrey V, Koller BH: Growth retardation, DNA repair defects, and lack of spermatogenesis in BRCA1-deficient mice. Mol Cell Biol 1999, 19(10):7061-7075.

105. Xu X, Qiao W, Linke SP, Cao L, Li WM, Furth PA, Harris CC, Deng CX: Genetic interactions between tumor suppressors Brca1 and p53 in apoptosis, cell cycle and tumorigenesis. Nat Genet 2001, 28(3):266-271.

106. Ramus SJ, Bobrow LG, Pharoah PD, Finnigan DS, Fishman A, Altaras M, Harrington PA, Gayther SA, Ponder BA, Friedman LS: Increased frequency of TP53 mutations in BRCA1 and BRCA2 ovarian tumours. Genes Chromosomes Cancer 1999, 25(2):91-96.

107. Liu X, Holstege H, van der Gulden H, Treur-Mulder M, Zevenhoven J, Velds A, Kerkhoven RM, van Vliet MH, Wessels LF, Peterse $J$, et al: Somatic loss of BRCA1 and p53 in mice induces mammary tumors with features of human BRCA1-mutated basal-like breast cancer. Proc Natl Acad Sci U S A 2007, 104(29):12111-12116.

108. Hakem R, de la Pompa JL, Elia A, Potter J, Mak TW: Partial rescue of Brca1 (5-6) early embryonic lethality by p53 or p21 null mutation. Nat Genet 1997, 16(3):298-302.

109. Holstege $H$, Joosse SA, van Oostrom CT, Nederlof PM, de Vries A, Jonkers J: High incidence of protein-truncating TP53 mutations in BRCA1-related breast cancer. Cancer Res 2009, 69(8):3625-3633.

110. Cao L, Kim S, Xiao C, Wang RH, Coumoul X, Wang X, Li WM, Xu XL, De Soto JA, Takai $H$, et al: ATM-Chk2-p53 activation prevents tumorigenesis at an expense of organ homeostasis upon Brca1 deficiency. EMBO J 2006, 25(10):2167-2177.

111. Tommiska J, Bartkova J, Heinonen M, Hautala L, Kilpivaara O, Eerola H, Aittomaki K, Hofstetter B, Lukas J, von Smitten K, et al: The DNA damage signalling kinase ATM is aberrantly reduced or lost in BRCA1/BRCA2deficient and ER/PR/ERBB2-triple-negative breast cancer. Oncogene 2008, 27(17):2501-2506.

112. Meijers-Heijboer $H$, van den Ouweland A, Klijn J, Wasielewski M, de Snoo A, Oldenburg R, Hollestelle A, Houben M, Crepin E, van Veghel-Plandsoen M, et al: Low-penetrance susceptibility to breast cancer due to $\mathrm{CHEK} 2\left(^{*}\right)$ 1100 delC in noncarriers of BRCA1 or BRCA2 mutations. Nat Genet 2002, 31(1):55-59.

113. Lee JS, Collins KM, Brown AL, Lee $\mathrm{CH}$, Chung JH: hCds1-mediated phosphorylation of BRCA1 regulates the DNA damage response. Nature 2000, 404(6774):201-204

114. Kim SS, Cao L, Li C, Xu X, Huber L, Chodosh LA, Deng CX: Uterus hyperplasia and increased carcinogen-induced tumorigenesis in mice carrying a targeted mutation of the Chk2 phosphorylation site in Brca1. Mol Cell Biol 2004, 24(21):9498-9507.

115. Abraham RT: Cell cycle checkpoint signaling through the ATM and ATR kinases. Genes Dev 2001, 15(17):2177-2196.

116. Chen J: Ataxia telangiectasia-related protein is involved in the phosphorylation of BRCA1 following deoxyribonucleic acid damage. Cancer Res 2000, 60(18):5037-5039.

117. Gatei M, Zhou BB, Hobson K, Scott S, Young D, Khanna KK: Ataxia telangiectasia mutated (ATM) kinase and ATM and Rad3 related kinase mediate phosphorylation of Brca1 at distinct and overlapping sites, In vivo assessment using phospho-specific antibodies. J Biol Chem 2001, 276(20):17276-17280. 
118. Tibbetts RS, Cortez D, Brumbaugh KM, Scully R, Livingston D, Elledge SJ, Abraham RT: Functional interactions between BRCA1 and the checkpoint kinase ATR during genotoxic stress. Genes Dev 2000, 14(23):2989-3002.

119. Kote-Jarai Z, Williams RD, Cattini N, Copeland M, Giddings I, Wooster R, TePoele RH, Workman P, Gusterson B, Peacock J, et al: Gene expression profiling after radiation-induced DNA damage is strongly predictive of BRCA1 mutation carrier status. Clinical cancer research: an official journal of the American Association for Cancer Research 2004, 10(3):958-963.

120. Farmer H, McCabe N, Lord CJ, Tutt AN, Johnson DA, Richardson TB, Santarosa M, Dillon KJ, Hickson I, Knights C, et al: Targeting the DNA repair defect in BRCA mutant cells as a therapeutic strategy. Nature 2005, 434(7035):917-921.

121. Bryant HE, Schultz N, Thomas HD, Parker KM, Flower D, Lopez E, Kyle S, Meuth M, Curtin NJ, Helleday T: Specific killing of BRCA2-deficient tumours with inhibitors of poly(ADP-ribose) polymerase. Nature 2005, 434(7035):913-917.

122. McCabe N, Lord CJ, Tutt AN, Martin NM, Smith GC, Ashworth A: BRCA2deficient CAPAN-1 cells are extremely sensitive to the inhibition of Poly (ADP-Ribose) polymerase: an issue of potency. Cancer Biol Ther 2005, 4(9):934-936.

123. Shaheen M, Allen C, Nickoloff JA, Hromas R: Synthetic lethality: exploiting the addiction of cancer to DNA repair. Blood 2011, 117(23):6074-6082.

124. Weil MK, Chen AP: PARP inhibitor treatment in ovarian and breast cancer. Curr Probl Cancer 2011, 35(1):7-50

125. Strom CE, Johansson F, Uhlen M, Szigyarto CA, Erixon K, Helleday T: Poly (ADP-ribose) polymerase (PARP) is not involved in base excision repair but PARP inhibition traps a single-strand intermediate. Nucleic Acids Res 2011, 39(8):3166-3175.

126. Helleday T, Bryant HE, Schultz N: Poly(ADP-ribose) polymerase (PARP-1) in homologous recombination and as a target for cancer therapy. Cell Cycle 2005, 4(9):1176-1178.

127. Schultz N, Lopez E, Saleh-Gohari N, Helleday T: Poly(ADP-ribose) polymerase (PARP-1) has a controlling role in homologous recombination. Nucleic Acids Res 2003, 31(17):4959-4964.

128. de Murcia JM, Niedergang C, Trucco C, Ricoul M, Dutrillaux B, Mark M, Oliver FJ, Masson M, Dierich A, LeMeur M, et al: Requirement of poly(ADP-ribose) polymerase in recovery from DNA damage in mice and in cells. Proc Natl Acad Sci U S A 1997, 94(14):7303-7307.

129. Simbulan-Rosenthal CM, Haddad BR, Rosenthal DS, Weaver Z, Coleman A, Luo R, Young HM, Wang ZQ, Ried T, Smulson ME: Chromosomal aberrations in PARP(-/-) mice: genome stabilization in immortalized cells by reintroduction of poly(ADP-ribose) polymerase CDNA. Proc Natl Acad Sci U S A 1999, 96(23):13191-13196.

130. Bryant HE, Petermann E, Schultz N, Jemth AS, Loseva O, Issaeva N, Johansson F, Fernandez S, McGlynn P, Helleday T: PARP is activated at stalled forks to mediate Mre11-dependent replication restart and recombination. EMBO J 2009, 28(17):2601-2615.

131. Guha M: PARP inhibitors stumble in breast cancer. Nat Biotechnol 2011 29(5):373-374

132. Sakai W, Swisher EM, Karlan BY, Agarwal MK, Higgins J, Friedman C, Villegas E, Jacquemont C, Farrugia DJ, Couch FJ, et al: Secondary mutations as a mechanism of cisplatin resistance in BRCA2-mutated cancers. Nature 2008, 451(7182):1116-1120.

133. Dhillon KK, Swisher EM, Taniguchi T: Secondary mutations of BRCA1/2 and drug resistance. Cancer Sci 2011, 102(4):663-669.

134. Rottenberg S, Jaspers JE, Kersbergen A, van der Burg E, Nygren AO, Zander SA, Derksen PW, de Bruin M, Zevenhoven J, Lau A, et al: High sensitivity of BRCA1-deficient mammary tumors to the PARP inhibitor AZD2281 alone and in combination with platinum drugs. Proc Natl Acad Sci U S A 2008, 105(44):17079-17084.

135. Issaeva N, Thomas HD, Djureinovic T, Jaspers JE, Stoimenov I, Kyle S, Pedley N, Gottipati P, Zur R, Sleeth K, et al: 6-thioguanine selectively kills BRCA2defective tumors and overcomes PARP inhibitor resistance. Cancer Res 2010, 70(15):6268-6276.
136. De Soto JA, Deng CX: PARP-1 inhibitors: are they the long-sought genetically specific drugs for BRCA1/2-associated breast cancers? Int J Med Sci 2006, 3(4):117-123.

137. Fong PC, Boss DS, Yap TA, Tutt A, Wu P, Mergui-Roelvink M, Mortimer P, Swaisland H, Lau A, O'Connor MJ, et al: Inhibition of poly(ADP-ribose) polymerase in tumors from BRCA mutation carriers. N Eng J Med 2009, 361(2):123-134.

doi:10.1186/2045-3701-3-11

Cite this article as: Zhang: The role of BRCA1 in homologous recombination repair in response to replication stress: significance in tumorigenesis and cancer therapy. Cell \& Bioscience 2013 3:11.

\section{Submit your next manuscript to BioMed Central and take full advantage of:}

- Convenient online submission

- Thorough peer review

- No space constraints or color figure charges

- Immediate publication on acceptance

- Inclusion in PubMed, CAS, Scopus and Google Scholar

- Research which is freely available for redistribution

Submit your manuscript at www.biomedcentral.com/submit
C Biomed Central 